\title{
OPEN
}
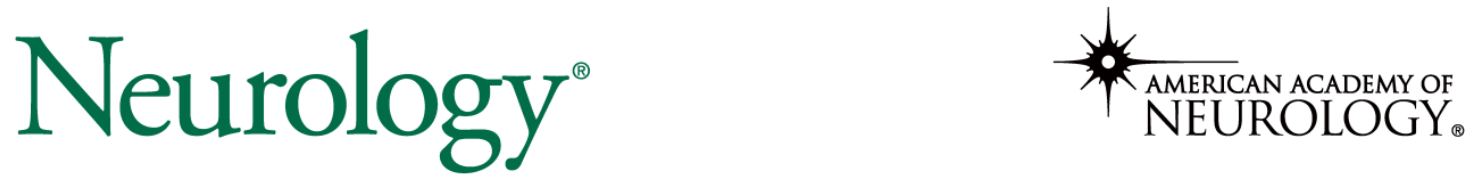

The most widely read and highly cited peer-reviewed neurology journal

The Official Journal of the American Academy of Neurology

Neurology Publish Ahead of Print

DOI: 10.1212/WNL.0000000000200024

\section{Revise the UDDA to Align the Law with Practice through Neuro-Respiratory Criteria}

Author(s):

Adam Omelianchuk, $\mathrm{PhD}^{1}$; James Bernat, $\mathrm{MD}^{2}$; Art Caplan, $\mathrm{PhD}^{3}$; David Greer, $\mathrm{MD}^{4}$; Christos Lazaridis, $\mathrm{MD}^{5}$; Ariane Lewis, $\mathrm{MD}^{6}$; Thaddeus Pope, $\mathrm{PhD}^{7}$; Lainie Friedman Ross, $\mathrm{PhD}^{8,9}$; David Magnus, $\mathrm{PhD}^{10}$

\section{Corresponding Author:}

David Magnus

dmagnus@stanford.edu

This is an open access article distributed under the terms of the Creative Commons AttributionNonCommercial-NoDerivatives License 4.0 (CC BY-NC-ND), which permits downloading and sharing the work provided it is properly cited. The work cannot be changed in any way or used commercially without permission from the journal.

Neurology® Published Ahead of Print articles have been peer reviewed and accepted for publication. This manuscript will be published in its final form after copyediting, page composition, and review of proofs. Errors that could affect the content may be corrected during these processes. 
Affiliation Information for All Authors: 1. Stanford Center for Biomedical Ethic; 2. Dartmouth Geisel School of Medicine; 3. NYU Grossman School of Medicine; 4. Boston University School of Medicine; 5. University of Chicago Medical Center; 6. NYU Langone Medical Center; 7. Mitchell Hamline School of Law; 8. Institute for Translational Medicine; 9. University of Chicago; 10. Stanford Center for Biomedical Ethics

\section{Contributions:}

Adam Omelianchuk: Drafting/revision of the manuscript for content, including medical writing for content; Study concept or design

James Bernat: Drafting/revision of the manuscript for content, including medical writing for content; Study concept or design

Art Caplan: Drafting/revision of the manuscript for content, including medical writing for content; Study concept or design

David Greer: Drafting/revision of the manuscript for content, including medical writing for content; Study concept or design

Christos Lazaridis: Drafting/revision of the manuscript for content, including medical writing for content; Study concept or design

Ariane Lewis: Drafting/revision of the manuscript for content, including medical writing for content; Study concept or design

Thaddeus Pope: Drafting/revision of the manuscript for content, including medical writing for content; Study concept or design

Lainie Friedman Ross: Drafting/revision of the manuscript for content, including medical writing for content; Study concept or design

David Magnus: Drafting/revision of the manuscript for content, including medical writing for content; Study concept or design

Number of characters in title: 82

Abstract Word count: $\mathrm{x}$

Word count of main text: 3156

References: 36

Figures: 0

Tables: 0 
Search Terms: [ 84 ] All Ethics in Neurology/Legal issues, [ 85 ] Brain death

Study Funding: The authors report no targeted funding

Disclosures: All authors are observers participating in the drafting of the revision of the Uniform Declaration of Death Act by the Uniform Law Commission except Dr. Lazaridis.

Abstract: Although the Uniform Determination of Death Act (UDDA) has served as a model statute for 40 years, there is a growing recognition that the law must be updated. One issue being considered by the Uniform Law Commission's Drafting Committee to revise the UDDA is whether the text "all functions of the entire brain, including the brainstem" should be changed. Some argue that the absence of diabetes insipidus indicates that some brain functioning continues in many individuals who otherwise meet the "accepted medical standards" like the American Academy of Neurology's. The concern is that the legal criteria and the medical standards used to determine death by neurological criteria are not aligned. We argue for the revision of the UDDA to more accurately specify legal criteria which align with the medical standards: brain injury leading to permanent loss of a) the capacity for consciousness, b) the ability to breathe spontaneously, and c) brainstem reflexes. We term these criteria "neuro-respiratory criteria" and show that they are well-supported in the literature for physiological and social reasons justifying their use in the law. 
At the end of the 1970s, neurological criteria for death were recognized in roughly half of the United States, resulting in a confusing legal landscape. To achieve uniformity across state lines and alignment of the law with medical practice, the President's Commission for the Study of Ethical Problems in Medicine and Biomedical and Behavior Research recommended state legislators adopt The Uniform Determination of Death Act (UDDA): ${ }^{1}$

An individual who has sustained either 1) irreversible cessation of circulatory and respiratory functions or 2) irreversible cessation of all functions of the entire brain, including the brainstem, is dead. A determination of death must be made in accordance with accepted medical standards.

Though it has served as a model statute for 40 years, and has been embraced in whole or in part throughout the United States, ${ }^{2}$ there is a growing recognition that the UDDA must be updated. ${ }^{3-5}$ The Uniform Law Commission recently approved a Study Committee's recommendation to form a Drafting Committee that should submit its proposed UDDA revisions by July 2023. Meanwhile, Nevada, Oklahoma, and Texas have already moved to amend their own UDDA statutes (Nev. A.B. 424 [2017], Okla. H.B. 1896 [2021], Tex. H.B. 4329 [2021]). Contentious aspects of the UDDA include interpretation of the phrases "all functions of the entire brain" (vs. some specific set of functions), and "accepted medical standards" (should they be specifically named or not?), and whether accommodations are needed to address religious or principled objections to determining death by neurological criteria (DNC). ${ }^{6-9}$ Here, we propose a solution to the alleged inconsistency between the meaning of "all functions of the entire brain" and "accepted medical standards" by transitioning from an anatomical approach to DNC to a functional approach, like the approach to death by circulatory criteria. This change will align the law with medical practice, bolster confidence among examiners in 
the reliability of the currently accepted medical standards, and transparently communicate to the public what the standards are expected to assess.

The currently accepted medical standards for DNC (published by the American Academy of Neurology in 2010 and the Society of Critical Care Medicine, American Academy of Pediatrics, and Child Neurology Society in 2011) ${ }^{10-12}$ require documentation of an injury that explains the loss of brain function, the exclusion of confounding conditions, and a clinical examination that demonstrates unarousable unresponsiveness, brainstem areflexia, and apnea. Some argue that the absence of diabetes insipidus in many individuals who meet these standards indicates that some functions of the brain continue after pronouncement of death, namely those in the neurosecretory hypothalamus that regulate salt and water balance. ${ }^{13,14}$ With this in mind, a Nature editorial argued, "The time has come for a serious discussion on redrafting laws that push doctors towards a form of deceit"(p. 570). ${ }^{15}$ To align the law with practice, either the "accepted medical standards" must include a more demanding set of tests that exclude neurosecretory functioning or the text requiring cessation of "all functions of the entire brain" must be revised. ${ }^{16,17}$

At some level, the criteria used to determine death must be a matter of convention and consensus. ${ }^{18,19}$ The relevant question is not whether any brain functions remain, but, rather, whether those functions contradict a determination of death. Unlike consciousness, responsiveness, or spontaneous respiratory effort, outside of a discussion about the phrase "all functions of the entire brain," the presence of neurosecretory functioning is not recognized as a contradiction to determination of death. ${ }^{20-25}$ While we welcome further debate on its significance, we see no reason to reject the 
recommendations of consensus statements like that of the World Brain Death Project's ${ }^{26}$ that the persistence of neurosecretory function is consistent with DNC.

Therefore, we support revision of the UDDA to more accurately specify legal criteria which align with the medical standards: brain injury leading to permanent loss of a) the capacity for consciousness, b) the ability to breathe spontaneously, and c) brainstem reflexes.3,4 We term these amended criteria "neuro-respiratory criteria." We recognize that there may be different and competing reasons to believe why neurorespiratory criteria are appropriate, as there is even disagreement about this amongst us, but we all agree that the law would be more clearly aligned with practice if the phrase "all functions of the entire brain" were replaced with language clearly specifying neurorespiratory criteria. The use of neuro-respiratory criteria is well-supported in the literature for physiological and social reasons justifying its use in the law.

\section{Worldwide Support for Neuro-Respiratory Criteria}

The motivation to declare DNC arose in the context of the critical care setting in which some ventilator-dependent patients were found to be comatose, lacked the capacity to initiate breathing, and no longer had reflexes that mediate pupillary reaction to bright light, spontaneous eye-tracking of objects when the head is abruptly turned, and cough or gag responses. ${ }^{27}$ According to the 1981 President's Commission's report, ${ }^{1}$ which articulated justifications for the UDDA, neurological criteria for death, like circulatory criteria, provide sufficient evidence for the death of the patient and are to be used if there is reason to believe circulatory functioning does not reliably indicate the presence of life.

Many of the arguments made by the President's Commission in Defining Death are consistent with the neuro-respiratory criterion. The "whole-brain" formulation 
never meant that every neuron had to fail; rather, it was meant to contrast with the socalled "higher brain" formulation, according to which the permanent loss of consciousness alone is decisive for determining death. "What is missing in the dead," the drafters argued, "is a cluster of attributes, all of which form part of an organism's responsiveness to its internal and external environment" (p. 36). The relevant "cluster of attributes" becomes clearer in their explanation of the language of "all functions of the entire brain, including the brain stem:"

This may be thought doubly redundant, but at least it should make plain the intent to exclude any patient who has lost only "higher" brain functions or, conversely, who maintains those functions but has suffered solely a direct injury to the brain stem which interferes with the vegetative functions of the body (p. 75, emphasis original).

Thus, if one is conscious or spontaneously breathes, one is not dead. While not explicitly stated, the implication is that if the cause of brain injury is known and confounding factors like hypothermia or drug intoxication are excluded, then permanent loss of the capacities for consciousness and the drive to breathe clinically indicate the permanent loss of the relevant "cluster of attributes" necessary for an organism to live (p. 36).

These attributes are clearly affirmed in the U.K. by the Academy of Royal Medical Colleges' Code of Practice for Diagnosing and Confirming Death. ${ }^{28}$ It states, "when the brain-stem has been damaged in such a way, and to such a degree, that its integrative functions (which include the neural control of cardiac and pulmonary function and consciousness) are irreversibly destroyed, death of the individual has occurred" (p. 13). As to the definition of death, the Royal Colleges assert that:

Death entails the irreversible loss of those essential characteristics which are necessary to the existence of a living human person and, thus, the definition of death should be regarded as the irreversible loss of the capacity for consciousness, combined with irreversible loss of the capacity to breathe (p. 11). 
The relationship between the destruction of the brainstem's “integrative functions" and the irreversible loss of the capacities for consciousness and the drive to breathe could not be clearer. Supporters of the brainstem formulation of DNC in the U.K. have maintained for decades that neuro-respiratory criteria are philosophically and culturally accepted, not only because of their critical importance for continued life, but also because they represent at the neurophysiological level the departure of the "conscious soul" and the "breath of life." 29,30

The President's Council on Bioethics' 2008 white paper Controversies in the Determination of Death is another landmark document that supports neuro-respiratory criteria. ${ }^{31}$ After reviewing the criticisms of the 1981 President's Commission's report, the majority view of the President's Council ("Position Two") was that DNC should be accepted as a way to determine the loss of the organism's capacity to perform its "vital work" (p. 60). The authors noted that the loss of the organism's capacity to engage in need-driven interaction with its environment, sensing what it needs (oxygen) and acting to meet those needs (striving to take in air), is what marks the end of the organism. ${ }^{2}$ This vital activity was explicitly operationalized in terms of neuro-respiratory criteria: "If there are no signs of consciousness and if spontaneous breathing is absent and if the best clinical judgment is that these neurophysiological facts cannot be reversed, Position Two would lead us to conclude that a once-living patient has now died" (p. 64, emphasis original). Like the U.K. model, Position Two further says, "From a philosophicalbiological perspective, it becomes clear that a human being with a destroyed brainstem has lost the functional capacities that define organismic life" (p. 66). Although they did not recommend changing the law to a "brainstem-only" formulation, they did clearly 
recommend using neuro-respiratory criteria to determine what they call "total brain failure" (or DNC) (p. 12).33

Further support for neuro-respiratory criteria can be adduced from two other representative professional societies. First, the Canadian Medical Association's 2006 report on the neurological determination of death 34 recommends that the "concept and definition of neurological death" be defined "as the irreversible loss of the capacity for consciousness combined with the irreversible loss of all brain stem functions [named elsewhere in the document], including the capacity to breathe" (p. S3). Second, the World Health Organization's 2012 statement on death criteria says, "Death occurs when there is permanent loss of capacity for consciousness and loss of all brainstem functions" (p. 31).35 Although the capacity to breathe is not explicitly mentioned, its loss is implied since they recognize that "respiratory arrest" is "secondary to the loss of brainstem function" (p. 13).

The most recent highly influential publication to acknowledge neuro-respiratory criteria is the World Brain Death Project (2020), an international consensus statement endorsed by 5 world federations and numerous medical societies. They recommended that neurological criteria for death be defined as "the complete and permanent loss of brain function as defined by an unresponsive coma with loss of capacity for consciousness, brainstem reflexes, and the ability to breathe independently" (p. 1081). ${ }^{26}$

One final note: the President's Commission, the Royal Medical Colleges, the President's Council, the Canadian Medical Association, the World Health Organization, and the World Brain Death Project all highlighted the importance of brainstem functioning for the capacities of consciousness and spontaneous breathing. The overlap of functions attributable to the brainstem nuclei - emotion, wakefulness and sleep, 
basic attention, and of course consciousness itself - are essential for the homeostatic balance of a living organism. ${ }^{36}$ The principal nuclei involved in modulating cortical activation lie in the upper pons and midbrain, however lower brainstem structures have been also implicated. Detailed examination of the functions of all clinically accessible brainstem nuclei increases certainty that the functions of consciousness and spontaneous breathing have been permanently lost.

\section{Advantages of Neuro-Respiratory Criteria}

We recognize that there can be varying philosophical, religious, cultural,

metaphysical, or biological views on when death occurs, but it is necessary for the law to clearly stipulate legal criteria for determining death and for these criteria to align with medical standards. ${ }^{6}$ As we have demonstrated, neuro-respiratory criteria, which have the advantage of basing the determination of death on the loss of key vital functioning rather than anatomical mortality (e.g. "whole-brain death," "brainstem death," "cardiac death") or the presence of cellular electrical activity, are widely accepted and should be incorporated into the UDDA.

When the neuro-respiratory criteria are satisfied, they afford just as bright a line between life and death as the accepted medical standards for circulatory criteria. Though this "bright line" is constructed for social purposes, it is rooted in observable facts, enabling confidence in the determination and the ability to make the distinction between life and death in a timely and efficient manner. 34 These purposes included determining when the grieving process begins, when a marriage ends, when lifeinsurance pays out, when constitutional rights no longer apply, when multiple vital organs can be procured, when requests for autopsy are initiated, and when plans for burial begin. 39 


\section{Conclusion}

Although additional revisions to the UDDA are necessary to address other concerns, such as whether the law should specify the medical standards themselves rather than loosely referring to "accepted medical standards," or whether accommodations are needed to address religious or principled objections to DNC, we recommend that the first sentence of the UDDA be revised to reference cessation of neuro-respiratory functions to bring the law in alignment with practice. Rather than require "irreversible cessation of all functions of the entire brain, including the brainstem," the UDDA should instead require "brain injury leading to permanent loss of a) the capacity for consciousness, b) the ability to breathe spontaneously, and c) brainstem reflexes.” 


\section{References}

1. President's Commission for the Study of Ethical Problems in Medicine and Biomedical and Behavioral Research. Defining death: Medical, legal and ethical issues in the determination of death. Washington, D.C.: President's Commission for the Study of Ethical Problems in Medicine and Biomedical and Behavioral Research; 1981.

2. Lewis A, Cahn-Fuller K, Caplan A. Shouldn't dead be dead?: The search for a uniform definition of death. J Law Med Ethics. 2017;45:112-128.

3. Lewis A, Bonnie RJ, Pope T, et al. Determination of death by neurologic criteria in the United States: The case for revising the Uniform Determination of Death Act. J Law Med Ethics. 2019;47:9-24.

4. Lewis A, Bonnie RJ, Pope T. It's time to revise the Uniform Determination of Death Act. Ann Intern Med. American College of Physicians; 2020;172:143-144.

5. Shewmon DA. Statement in support of revising the Uniform Determination of Death Act and in opposition to a proposed revision. J Med Philos. Epub 2021 May 14 .

6. Pope T. Brain death and the law: Hard cases and legal challenges. Hastings Center Report. 2018;48:S46-S48.

7. Lewis A, Greer D. Current controversies in brain death determination. Nat Rev Neurol. 2017;13:505-509.

8. Olick RS. Brain death, religious freedom, and public policy: New Jersey's landmark legislative initiative. Kennedy Institute of Ethics Journal. 1991;1:275-288.

9. Johnson LSM. The case for reasonable accommodation of conscientious objections to declarations of brain death. Bioethical Inquiry. 2016;13:105-115.

10. Wijdicks EFM, Varelas PN, Gronseth GS, Greer DM. Evidence-based guideline update: Determining brain death in adults: Report of the Quality Standards Subcommittee of the American Academy of Neurology. Neurology. 2010;74:19111918.

11. Nakagawa TA, Ashwal S, Mathur M, et al. Guidelines for the determination of brain death in infants and children: An update of the 1987 Task Force recommendations. Crit Care Med. 2011;39:2139-2155.

12. Lewis A, Bernat JL, Blosser S, et al. An interdisciplinary response to contemporary concerns about brain death determination. Neurology. 2018;90:423-426.

13. Nair-Collins M, Northrup J, Olcese J. Hypothalamic-pituitary function in brain death: A review. J Intensive Care Med. 2014;31:41-50. 
14. Halevy A, Brody B. Brain death: reconciling definitions, criteria, and tests. Annals Of Internal Medicine. 1993;119:519-525.

15. Delimiting death. Nature. 2009;461:570-570.

16. Bernat JL, Dalle Ave AL. Aligning the criterion and tests for brain death. Cambridge Quarterly of Healthcare Ethics. 2019;28:635-641.

17. Dalle Ave AL, Bernat JL. Inconsistencies between the criterion and tests for brain death. J Intensive Care Med. SAGE Publications Inc STM; 2020;35:772-780.

18. Capron AM, Kass LR. Statutory definition of the standards for determining human death: An appraisal and a proposal. U Pa L Rev. 1972;121:87.

19. Capron AM. Death, definition and determination of: II. Legal Issues in Pronouncing Death. In: Post SG, editor. Encyclopedia of Bioethics. 3rd ed. New York, NY: Macmillan Reference USA; 2004. p. 608-615.

20. Schrader H, Krogness K, Aakvaag A, Sortland O, Purvis K. Changes of pituitary hormones in brain death. Acta Neurochir (Wien). 1980;52:239-248.

21. Outwater KM, Rockoff MA. Diabetes insipidus accompanying brain death in children. Neurology. 1984;34:1243-1246.

22. Fiser DH, Jimenez JF, Wrape V, Woody R. Diabetes insipidus in children with brain death. Crit Care Med. 1987;15:551-553.

23. Arita K, Uozumi T, Oki S, Ohtani M, Taguchi H, Morio M. Hypothalamic pituitary function in brain death patients--from blood pituitary hormones and hypothalamic hormones. No Shinkei Geka. 1988;16:1163-1171.

24. Sugimoto T, Sakano T, Kinoshita Y, Masui M, Yoshioka T. Morphological and functional alterations of the hypothalamic-pituitary system in brain death with long-term bodily living. Acta Neurochir (Wien). 1992;115:31-36.

25. Brandt SA, Angstwurm $H$. The relevance of irreversible loss of brain function as a reliable sign of death. Dtsch Arztebl Int. 2018;115:675-681.

26. Greer DM, Shemie SD, Lewis A, et al. Determination of brain death/death by neurologic criteria: The World Brain Death Project. JAMA. 2020;324:1078-1097.

27. Beecher HK, Adams RD, Barger AC. A definition of irreversible coma: Report of the Ad Hoc Committee of the Harvard Medical School to examine the definition of brain death. JAMA. 1968;205:337-340.

28. Academy of Royal Medical Colleges. A code of practice for the diagnosis and confirmation of death [online]. London: Academy of Royal Medical Colleges; 2008 p. 1-42. Accessed at: https://www.aomrc.org.uk/reports-guidance/ukdec-reports- 
and-guidance/code-practice-diagnosis-confirmation-death/. Accessed June 4, 2021.

29. Pallis C, Harley DH. ABC of brainstem death. $2^{\text {nd }}$ ed. London: BMJ Publishing Group; 1996.

30. Pallis C. On the brainstem criterion of death. In: Youngner SJ, Arnold RM, Schapiro R, editors. The Definition of Death: Contemporary Controversies. Baltimore, MD: John Hopkins University Press; 1999. p. 93-100.

31. President's Council on Bioethics. Controversies in the determination of death: A white paper of the President's Council on Bioethics. Washington, D.C.: President's Council on Bioethics; 2008.

32. Rubenstein A. What and when is death? The New Atlantis. 2009.:29-45.

33. Wijdicks EFM. The transatlantic divide over brain death determination and the debate. Brain. 2012;135:1321-1331.

34. Shemie SD, Doig C, Dickens B, et al. Severe brain injury to neurological determination of death: Canadian forum recommendations. CMAJ. 2006;174:S1S12.

35. World Health Organization. International guidelines for the determination of death - Phase I [online]. Ottawa, Ontario: Canadian Blood Services; 2012. Accessed at: https://www.who.int/patientsafety/montreal-forum-report.pdf. Accessed June 7, 2021.

36. Parvizi J, Damasio A. Consciousness and the brainstem. Cognition. 2001;79:135160.

37. Truog RD. Defining death-Making sense of the case of Jahi Mcmath. JAMA. 2018;319:1859-1860.

38. Khushf G. A matter of respect: A defense of the dead donor rule and of a "wholebrain" criterion for determination of death. J Med Philos. 2010;35:330-364.

39. Magnus D. A defense of the dead donor rule. Hastings Center Report. 2018;48:S36-S38. 


\title{
Neurology
}

\author{
Revise the UDDA to Align the Law with Practice through Neuro-Respiratory Criteria \\ Adam Omelianchuk, James Bernat, Art Caplan, et al. \\ Neurology published online January 25, 2022 \\ DOI 10.1212/WNL.0000000000200024
}

This information is current as of January 25, 2022

Updated Information \&
Services

Citations

Subspecialty Collections

Errata

Permissions \& Licensing

Reprints including high resolution figures, can be found at: http://n.neurology.org/content/early/2022/01/25/WNL.0000000000200024.f ull

This article has been cited by 1 HighWire-hosted articles: http://n.neurology.org/content/early/2022/01/25/WNL.0000000000200024.f ull\#\#otherarticles

This article, along with others on similar topics, appears in the following collection(s):

All Ethics in Neurology/Legal issues

http://n.neurology.org/cgi/collection/all_ethics_in_neurology_legal_issues Brain death

http://n.neurology.org/cgi/collection/brain_death

An erratum has been published regarding this article. Please see next page or:

/content/100/10/496.2.full.pdf

Information about reproducing this article in parts (figures,tables) or in its entirety can be found online at:

http://www.neurology.org/about/about_the_journal\#permissions

Information about ordering reprints can be found online:

http://n.neurology.org/subscribers/advertise

Neurology ${ }^{\circledR}$ is the official journal of the American Academy of Neurology. Published continuously since 1951, it is now a weekly with 48 issues per year. Copyright Copyright (C) 2022 The Author(s). Published by Wolters

Kluwer Health, Inc. on behalf of the American Academy of Neurology.. All rights reserved. Print ISSN:

0028-3878. Online ISSN: 1526-632X.






\title{
Disputes \& Debates: Editors' Choice
}

Steven Galetta, MD, FAAN, Editor

Aravind Ganesh, MD, DPhil, FRCPC, Deputy Editor

Ariane Lewis, MD, Deputy Editor

James E. Siegler III, MD, Deputy Editor

\section{Editors' Note: Infratentorial Brain Injury Among Patients Suspected of Death by Neurologic Criteria: A Systematic Review and Meta-analysis \\ In "Infratentorial Brain Injury Among Patients Suspected of Death by Neurologic Criteria:} A Systematic Review and Meta-analysis," Briard et al. report that based on a review of 21 studies, the prevalence of (1) infratentorial brain injury among patients with suspected death by neurologic criteria (DNC) was $2 \%-16 \%$ and (2) isolated brainstem death was $1 \%-4 \%$. Machado pointed out that a series of 4 patients with infratentorial brain injury who initially had isolated brainstem death subsequently progressed to whole-brain death. The study on these patients was included in Briard's review. He also commented that Jahi McMath, who was declared dead by neurologic criteria based on both clinical evaluation and ancillary testing after hypoxic-ischemic brain injury, had a lesion in her pons and was not dead by neurologic criteria because she did not have a complete intracranial circulatory arrest. This case has been discussed extensively in the literature, but Briard and Chassé did not offer comments on it. However, they agree with Machado that additional research is needed to understand the determination of DNC in patients with infratentorial brain injury.

\section{Reader Response: Infratentorial Brain Injury Among Patients Suspected of Death by Neurologic Criteria: A Systematic Review and Meta-analysis}

\author{
Calixto Machado (Havana) \\ Neurology ${ }^{\circledR}$ 2023;100:494-495. doi:10.1212/WNL.0000000000207091
}

The article by Briard et al. ${ }^{1}$ affirmed that infratentorial brain injury is relatively uncommon among patients suspected of death by neurologic criteria (DNC) and that isolated brainstem death seems to progress to whole-brain death in most cases.

On the contrary, Varelas et al. reported 4 patients with catastrophic posterior fossa injuries who fulfilled the UK criteria for DNC. Those 4 patients showed preservation of supratentorial cerebral blood flow (CBF), which disappeared between 2 and 6 days. This allowed for a diagnosis of DNC, according to the whole brain US criteria. Hence, the report concluded that if CBF assessment is used as an ancillary test, there is no difference between those patients and those who experience brain death due to supratentorial lesions. ${ }^{2-4}$

If a posterior fossa lesion does not produce extreme intracranial pressure, a complete intracranial circulatory arrest does not occur. For example, brain death was declared in the well-known case of Jahi McMath, but ancillary tests performed 9 months after the initial brain insult showed conservation of intracranial structures, EEG activity, and autonomic reactivity to the "Mother Talks" stimulus, rejecting the diagnosis of DNC. An MRI study of Jahi McMath's brain 
demonstrated a huge lesion in the pons. ${ }^{5}$ Further research and discussion are necessary regarding the use of confirmatory tests for DNC diagnosis in the presence of primary posterior fossa lesions.

1. Briard JN, Plourde G, Nitulescu R, et al. Infratentorial brain injury among patients suspected of death by neurologic criteria: a systematic review and meta-analysis. Neurology. 2023;100(4):e443-e453. doi: 10.1212/WNL.0000000000201449.

2. Manara A, Varelas P, Wijdicks EF. Brain death in patients with "isolated" brainstem lesions: a case against controversy. J Neurosurg Anesthesiol. 2019;31(2):171-173. doi: 10.1097/ANA.0000000000000568.

3. Varelas PN. Brainstem or entire brain-based declaration of death: is there a difference? Pract Neurol. 2016;16(2):85-86. doi: 10.1136/ practneurol-2015-001348.

4. Varelas PN, Brady P, Rehman M, et al. Primary posterior fossa lesions and preserved supratentorial cerebral blood flow: implications for brain death determination. Neurocrit Care. 2017;27(3):407-414. doi: 10.1007/s12028-017-0442-3.

5. Machado C. Brain death diagnosis in primary posterior fossa lesions. Neurol India. 2022;70(2):670-675. doi: 10.4103/00283886.344634 .

Copyright @ 2023 American Academy of Neurology

\section{Author Response: Infratentorial Brain Injury Among Patients Suspected of Death by Neurologic Criteria: A Systematic Review and Meta-analysis}

Joel Neves Briard (Montréal) and Michaël Chassé (Montréal)

Neurology ${ }^{\circledR}$ 2023;100:495. doi:10.1212/WNL.0000000000207092

We thank Dr. Machado for the interest in our article on the prevalence, characteristics, and evolution of infratentorial brain injury and isolated brainstem death among patients suspected of death by neurologic criteria (DNC). ${ }^{1}$

The cited study by Varelas and colleagues ${ }^{2}$ was included in our systematic review and contributed to its conclusions. Data from this study arerepresented in our mean prevalence estimates for both infratentorial brain injury and isolated brainstem death. Furthermore, the characteristics and evolution of isolated brainstem death patients described in this study were included among the 38 isolated brainstem death patients we found in the literature.

There is some evidence that the mechanism by which patients with isolated brainstem death eventually progress to whole-brain death includes progressive supratentorial hydrocephalus, intracranial hypertension, and venous drainage obstruction, but this evolution and its determinants have not yet been thoroughly validated in high-quality studies. ${ }^{3,4}$ We agree that further research is necessary to determine the clinical significance of preserved cerebral blood flow, perfusion, or neurophysiologic function in patients with a clinical examination consistent with the $\mathrm{DNC}^{5}$ and that expert consensus guidelines are needed to clarify how to best address individuals with brainstem areflexia after primary infratentorial brain injury.

1. Briard JN, Plourde G, Nitulescu R, et al. Infratentorial brain injury among patients suspected of death by neurologic criteria: a systematic review and meta-analysis. Neurology. 2023;100(4):e443-e453. doi: 10.1212/WNL.0000000000201449.

2. Varelas PN, Brady P, Rehman M, et al. Primary posterior fossa lesions and preserved supratentorial cerebral blood flow: implications for brain death determination. Neurocrit Care. 2017;27(3):407-414. doi: 10.1007/s12028-017-0442-3.

3. Kramer AH, Kromm JA, Doig CJ, Chassé M, Couillard PL. Neurological determination of death following infratentorial stroke: a population-based cohort study. Can J Neurol Sci. 2022;49(4):553-559. doi: 10.1017/cjn.2021.177.

4. Marcellino C, Braksick SA, Wijdicks EFM. How does the brain die after a massive posterior fossa lesion? Neurocrit Care. 2021;34(2): 686-690. doi: 10.1007/s12028-020-01147-3.

5. Plourde G, Briard JN, Shemie SD, Shankar JJS, Chassé M. Flow is not perfusion, and perfusion is not function: ancillary testing for the diagnosis of brain death. Can J Anaesth. 2021;68(7):953-961. doi: 10.1007/s12630-021-01988-2.

Copyright (c) 2023 American Academy of Neurology

Author disclosures are available upon request (journal@neurology.org). 


\section{Initial High-Efficacy Disease-Modifying Therapy in \\ Multiple Sclerosis}

A Nationwide Cohort Study

Neurology ${ }^{\circledR}$ 2023;100:496. doi:10.1212/WNL.0000000000201391

In the Research Article "Initial High-Efficacy Disease-Modifying Therapy in Multiple Sclerosis: A Nationwide Cohort Study" by Buron et al., ${ }^{1} 2$ authors were mistakenly omitted from the final manuscript. Dr. Danny Bech, MD, should appear as author \#5, and Dr. Sivagini Prakash, MD, should appear as author \#14. The article has been replaced by a version with the correct byline. The original version with the changes highlighted is available from a link in the corrected article. The authors regret the omission.

\section{Reference}

1. Buron M, Chalmer T, Sellebjerg F, et al. Initial high-efficacy disease-modifying therapy in multiple sclerosis: a nationwide cohort study. Neurology. 2020;95:e1041-e1051.

\section{Revise the Uniform Determination of Death Act to Align the Law With Practice Through Neurorespiratory Criteria}

Neurology ${ }^{\circledR}$ 2023;100:496. doi:10.1212/WNL.0000000000201063

In the Contemporary Issues in Practice, Education, \& Research article "Revise the Uniform Determination of Death Act to Align the Law With Practice Through Neurorespiratory Criteria" by Omelianchuk et al., ${ }^{1} 2$ block quotes were inadvertently omitted under the Worldwide Support for Neurorespiratory Criteria section, with the authors' words formatted as quotes. The article has been replaced by a corrected version. The original version with the changes highlighted is available from a link in the corrected article. The publisher regrets the errors.

\section{Reference}

1. Omelianchuk A, Bernat J, Caplan A, et al. Revise the Uniform Determination of Death Act to align the law with practice through neurorespiratory criteria. Neurology. 2022;98(13):532-536. 